\title{
Revisiting the former approach: Low-dose dopamine in kidney transplant recipients
}

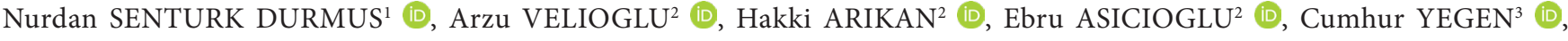 \\ Serhan TUGLULAR ${ }^{2}$ (D) \\ ${ }^{1}$ Department of Internal Medicine, School of Medicine, Marmara University, Istanbul, Turkey. \\ ${ }^{2}$ Division of Nephrology, Department of Internal Medicine, School of Medicine, Marmara University, Istanbul, Turkey \\ ${ }^{3}$ Department of General Surgery, School of Medicine, Marmara University, Istanbul, Turkey.
}

\section{Corresponding Author: Nurdan SENTURK DURMUS}

E-mail: nurdan_69@hotmail.com

Submitted: 03.01.2021 Accepted: 20.03.2021

\section{ABSTRACT}

Objective: We aim to evaluate the effects of low-dose dopamine (LDD) infusion $(0.5-2.5 \mathrm{~g} / \mathrm{kg} / \mathrm{min})$ on hemodynamic status and short-term graft function in kidney transplant recipients.

Materials and Methods: Patients who underwent kidney transplantation surgery between January 2007 and December 2016 were included in the study. Demographic and laboratory data, presence of delayed graft function, and the rates of rejection, graft loss, and mortality were recorded. The data were compared between patients with and without LDD treatment.

Results: A total of 126 patients were included in the study (M/F:50.8\%/49.2\%; mean age, $38.94 \pm 11.8$ years). Ninety-four patients (74.6\%) received living-donor transplants. Fifty-seven patients underwent LDD infusion in the postoperative period (LDD group), while 69 patients did not receive LDD infusion. Demographic and laboratory data of the patients did not significantly differ between groups. Nineteen patients in the LDD group experienced delayed graft function ( $\mathrm{p}=0.039)$. However, these patients tended to be older, have a longer dialysis period prior to transplantation, deceased and hypertensive donors. There was no significant difference in renal function at 6 months after transplantation between groups.

Conclusion: Although, LDD infusion increases kidney blood flow, we observed no significant effects on short-term graft function or patient survival between the LDD and non-LDD groups.

\section{INTRODUCTION}

Restoration of optimal blood flow is essential for achievement of proper graft function following appropriate surgical interventions and induction treatment. Although, intravenous hydration in the post-transplant period is regarded as the gold standard, the search continues for other methods or medications to increase renal blood flow in transplant recipients.

Dopamine is an endogenous catecholamine that exerts its effects through dopaminergic receptors. It affects the kidney via the dopamine agonist (DA1) receptor on the vascular smooth muscle of the kidney and the DA2 receptor in the presynaptic region. Activation of these receptors causes vasodilation, resulting in elevations in renal blood flow and glomerular filtration rate (GFR) [1]. The DA1 and DA2 receptors are also located on the proximal tubule, the thick ascending limb of the loop of Henle, and the collecting canal; dopamine inhibits $\mathrm{Na} / \mathrm{K}$-ATPase activity in these locations and contributes to the regulation of natriuresis and diuresis [2]. Furthermore, dopamine causes elevations in blood pressure, heart rate, and cardiac contractility through its actions on adrenergic receptors. The effects of dopamine are dosedependent. Low-dose dopamine (LDD) is defined as treatment at a dose of $0.5-2.5 \mu \mathrm{g} / \mathrm{kg} / \mathrm{min}$; at this dose, the drug only affects dopaminergic (renal) receptors. Therefore, it is not expected to affect other receptors and cause systemic side effects. Because of the status of dopamine as a positive inotropic agent, treatment with LDD has been suggested to increase renal blood flow, while improving GFR and urine output.

Low-dose dopamine has been used in the treatment of acute kidney injury and for renoprotection during cardiovascular surgery in the past but the evidence failed to support this effect. Its well-known side effects like increase in blood pressure,

How to cite this article: Durmus Senturk N, Velioglu A, Arikan A, Asicioglu E, Yegen C, Tuglular S. Revisiting the former approach: Low-dose dopamine in kidney transplant recipients. Marmara Med J 2021; 34(2):95-100. doi: 10.5472/marumj.943134 
heart rate, and cardiac contractility and lack of evidence for renoprotection, resulted in its widely abandonment [3, 4]. Furthermore, the use of dopamine has also been abandoned following renal transplantation mainly due to projecting evidence from cardiovascular surgery. Despite its proven ability to cause increased blood flow in the native kidney, there have been few studies regarding the effects of dopamine on denervated transplanted kidneys [3,5,6].

Low-dose dopamine treatment was used with an aim to increase renal blood flow early after renal transplantation at our institution until February 2013, but its use was abandoned due to accumulating evidence of lack of benefit for other indications mentioned above. The patients have been followed only with intravenous hydration applied as dictated by their volume status.

The present study was undertaken to retrospectively compare the historic cohort when LDD was used in the early postoperative period following kidney transplantation with the more recent cohort which only received intravenous hydration in the early postoperative period from early hemodynamic status and renal function perspective.

\section{MATERIALS and METHODS}

All patients older than 18 years of age who underwent renal transplantation between January 2007 and December 2016 were included in this study. Patients with primary non-functioning grafts and patients under 18 years of age were excluded. This study was approved by the institutional review board of Marmara University School of Medicine (approval number 09.2017.266).

\section{Immunosuppressive drug regimens}

In patients undergoing living donor kidney transplantation, calcineurin inhibitors and antimetabolites were initiated 2 days before surgery; patients with low immunological risk received basiliximab whereas anti-thymocyte globulin was used in patients undergoing deceased donor kidney transplantation and/or patients with high immunological risk for induction treatment. Calcineurin inhibitors and antimetabolites were initiated postoperatively in deceased donor kidney transplant recipients. All patients received $1 \mathrm{~g}$ of methylprednisolone at the time of anastomosis. Corticosteroid doses were tapered within 3 months postoperatively, and all patients were maintained on low-dose prednisolone.

\section{Peri - and post-transplantation follow-up}

A dedicated team performed all kidney transplantation procedures, using the standard anesthesia protocol. In the postoperative follow-up period, all patients received intravenous saline and 5\% dextrose for hydration. We included consecutive patients who underwent kidney transplantation between 2007 and 2013 in the LDD group. Dopamine was started intravenously at a rate of $2 \mu \mathrm{g} / \mathrm{kg} / \mathrm{min}$ during the operation and continued for the following 72 hours. Patients who underwent kidney transplantation between 2013 and 2016 did not receive LDD infusion, due to a change in protocol. The latter was the non-LDD group. All patients received intravenous hydration as described above. Demographics and clinical data were obtained retrospectively from the patients' files. Data regarding heart rate, blood pressure, plasma creatinine $(\mathrm{Cr})$, blood urea nitrogen, hemoglobin, and diuresis were retrospectively collected for the study during the first week after transplantation for all patients. Any intraoperative inotropic agent administration was recorded. The presence of delayed graft function was recorded. Graft function was determined using GFR, as calculated by the Modification of Diet in Renal Disease formula $(175 \times($ Serum $\mathrm{Cr})^{-1.154} \times(\text { Age })^{-0.203}(\times 0.742$ if female $)$ [7]; graft function and rejection rates were evaluated at 1,3 , and 6 months after transplantation. Mortality rate and graft loss data were also recorded. We compared the presence of delayed graft function, overall graft function, mortality, and graft loss between the LDD and non-LDD groups. Delayed graft function was defined as the need for one or more hemodialysis sessions after kidney transplantation [8] with $<70 \%$ reduction in the Cr level on posttransplant day 7, compared to the pretransplant level [9].

\section{Statistical analysis}

All data were analyzed using SPSS (version 22.0; IBM Corp., Armonk, NY, USA). Continuous descriptive variables are shown as means \pm standard deviations for those that exhibited a normal distribution and as medians (minimums - maximums) for those that did not exhibit a normal distribution. The $t$ test or Mann-Whitney U test was used for comparisons of continuous variables between the groups. The $\chi^{2}$ test was used for comparisons of categorical variables. In all analyses, $\mathrm{p}<0.05$ was considered to indicate statistical significance. Use of dopamine and other risk factors for the study endpoints (i.e., delayed graft function, graft loss at 6 months, mortality, and GFR values at 6 months) were analyzed by Cox regression analysis.

\section{RESULTS}

The study population consisted of 126 renal transplant patients (64 men [50.8\%] and 62 women [49.2\%]) with a mean age of $38.94 \pm 11.8$ (range, $18-67$ ) years. The most common primary renal disease was glomerulonephritis (32 patients, $25.4 \%$ ) while primary renal disease was unknown in $36(28.6 \%)$ patients. Twelve patients $(9.5 \%)$ had undergone preemptive transplantation, 91 patients $(72.2 \%)$ had received hemodialysis, and 23 patients $(18.3 \%)$ had received peritoneal dialysis treatment prior to transplantation. The mean duration of renal replacement therapy was $40.91 \pm 48.32$ (range, $1-216$ ) months. Ninety-four patients (74.6\%) underwent living donor transplantation; 32 patients (25.4\%) underwent deceased donor transplantation. The mean age of the donors was $44.24 \pm 11.67$ (range, 7 -65) years. Sixty-five donors (57.5\%) were women. Nine donors had a history of hypertension.

In total, $31(24.6 \%)$ patients had delayed renal function. Two patients had graft loss; one patient with a functioning graft died due to sepsis 5 months after transplantation. Fifty-seven patients (45.2\%) received LDD infusion for 72 hours postoperatively. Sixty-nine patients received only intravenous hydration without LDD after surgery. Of the twenty-three patients (18.3\%) who required intraoperative vasopressors, one was $(1.7 \%)$ in the 
LDD group (noradrenaline) while the remaining 22 patients (31.8\%) were in the non-LDD group.

There were no significant differences in sex, age, or etiology between the patient groups. Demographic and clinical data of patients in both groups are summarized in Table I. A summary of the laboratory and clinical findings of the patients during the postoperative follow-up period is shown in Table II. While there were no significant differences in changes in Cr level between the two patient groups, urine output was significantly higher in the non-LDD group on the first day postoperatively. The urine output levels at 6 months were found to be correlated in both groups with $\mathrm{Cr}$ levels at 1 day, 1 week, 1 month, and 3 months postoperatively $(r=0.322$, $\mathrm{p}<0.001 ; \mathrm{r}=0.776, \mathrm{p}<0.001 ; \mathrm{r}=0.868, \mathrm{p}<0.001$, respectively).

Table I. Comparison of demographic data of patients with and without LDD

\begin{tabular}{|c|c|c|c|}
\hline & $\begin{array}{l}\text { LDD patients } \\
\qquad(\mathrm{n}=57)\end{array}$ & $\begin{array}{c}\text { non-LDD } \\
\text { patients }(n=69)\end{array}$ & p value \\
\hline $\operatorname{Sex}(M / F)$ & $27 / 30$ & $37 / 32$ & 0.59 \\
\hline Age (years) & $40.82+12.3$ & $37.38+11.3$ & 0.106 \\
\hline Primary diseases & & & 0.054 \\
\hline Unknown & $16(28.1 \%)$ & $20(29 \%)$ & \\
\hline GN & $12(21.1 \%)$ & $20(29 \%)$ & \\
\hline HT & $13(22.8 \%)$ & $8(11.6 \%)$ & \\
\hline Polycystic Kidney & $4(7 \%)$ & $5(7.3 \%)$ & \\
\hline Disease & $2(3.5 \%)$ & $7(10.2 \%)$ & \\
\hline & $6(10.5 \%)$ & $5(7.3 \%)$ & \\
\hline & $2(3.5 \%)$ & $3(4.3 \%)$ & \\
\hline Amyloidosis & $2(3.5 \%)$ & $4(5.7 \%)$ & \\
\hline Pyelonephritis & 0 & $2(2.8 \%)$ & \\
\hline $\begin{array}{l}\text { Chronic Interstitial } \\
\text { Nephritis }\end{array}$ & & & \\
\hline $\begin{array}{l}\text { Renal Replacement } \\
\text { Therapy }\end{array}$ & $37(65 \%)$ & $54(78.3 \%)$ & 0.31 \\
\hline Hemodialysis & $16(28 \%)$ & $7(10.2 \%)$ & \\
\hline $\begin{array}{l}\text { Peritoneum Dialysis } \\
\text { Preemptive }\end{array}$ & $4(7 \%)$ & $8(11.5 \%)$ & \\
\hline $\begin{array}{l}\text { Duration of Renal } \\
\text { Replacement Therapy } \\
\text { (month) }\end{array}$ & $50.91+42.7$ & $32.23+51.3$ & 0.36 \\
\hline Transplant Type & & & \\
\hline Living & $36(63.2 \%)$ & $58(84 \%)$ & 0.013 \\
\hline Deceased & $21(36.8 \%)$ & $11(16 \%)$ & \\
\hline Donor Age (year) & 42.69 & 45.03 & 0.33 \\
\hline Donor Sex $(M / F)^{*}$ & $21 / 23$ & $27 / 42$ & 0.43 \\
\hline Donor HT & $1(1.7 \%)$ & $8(11.5 \%)$ & 0.15 \\
\hline
\end{tabular}

LDD: Low Dose Dopamine, GN: Glomerulonephritis, HT: Hypertension, DM: Diabetes Mellitus, VUR: Vesicoureteral Reflux.
Delayed renal function was observed in 19 (33.3\%) patients in the LDD group and 12 patients $(17.3 \%)$ in the non-LDD group ( $p=0.039$ ). Long-term renal replacement therapy, recipient age, deceased donor transplantation, and donor hypertension values were significantly different between patients with and without delayed graft function (Table III). Regression analysis showed that LDD infusion did not influence factors associated with delayed graft function.

While 36 patients (63.1\%) in the LDD group had GFR $>60 \mathrm{ml} /$ min at 6 months postoperatively, 38 patients $(55.1 \%)$ in the nonLDD group had GFR $>60 \mathrm{ml} / \mathrm{min}$ at 6 months postoperatively $(\mathrm{p}=0.37)$. There was no significant difference between the two groups in terms of renal function at 6 months (Table II).

Table II. Comparison of laboratory and clinical follow-up data of patients with and without $L D D$

\begin{tabular}{|l|c|c|c|}
\hline & $\begin{array}{c}\text { LDD patients } \\
(\mathbf{n}=\mathbf{5 7})\end{array}$ & $\begin{array}{c}\text { non-LDD } \\
\text { patients (n=69) }\end{array}$ & p value \\
\hline Preop Hgb (g/L) & $11.34+1.60$ & $11.24+1.66$ & 0.74 \\
\hline Preop Alb (g/L) & $4.15+0.57$ & $4.12+0.61$ & 0.74 \\
\hline 1st day Cr (mg/dL) & $5.97+2.77$ & $4.89+2.1$ & 0.22 \\
\hline 1st week Cr (mg/dL) & $2.59+2.46$ & $1.84+1.5$ & 0.35 \\
\hline 1st month Cr (mg/dL) & $1.43+1.6$ & $1.31+0.56$ & 0.55 \\
\hline 3rd month Cr (mg/dL) & $1.18+0.7$ & $1.27+0.43$ & 0.34 \\
\hline 6th month Cr (mg/dL) & $1.23+0.6$ & $1.3+0.7$ & 0.54 \\
\hline $\begin{array}{l}\text { Postop 1st day input } \\
\text { fluid (mL) }\end{array}$ & $3798+1735$ & $3932+1315$ & 0.73 \\
\hline $\begin{array}{l}\text { Postop 1st day output } \\
\text { fluid (mL) }\end{array}$ & $2465+1603$ & $3779+1794$ & 0.006 \\
\hline $\begin{array}{l}\text { 1st day mean SBP } \\
\text { (mmHg) }\end{array}$ & $141.31+14.3$ & $133.45+19.5$ & 0.12 \\
\hline $\begin{array}{l}\text { 1st day mean DBP } \\
\text { (mmHg) }\end{array}$ & $81.84+8.8$ & $81.94+11.8$ & 0.97 \\
\hline $\begin{array}{l}\text { 1st day mean pulse } \\
\text { (minute) }\end{array}$ & $91.43+15.7$ & $88.95+11.6$ & 0.47 \\
\hline $\begin{array}{l}\text { Postop 7th day input } \\
\text { fluid (mL) }\end{array}$ & $3420+1463$ & $3700+1240$ & 0.43 \\
\hline $\begin{array}{l}\text { Postop 7th day output } \\
\text { fluid (mL) }\end{array}$ & $3147+1787$ & $3861+1385$ & 0.81 \\
\hline $\begin{array}{l}\text { 7th day mean SBP } \\
\text { (mmHg) }\end{array}$ & $145.66+12.4$ & $141.92+15.5$ & 0.38 \\
\hline $\begin{array}{l}\text { 7th day mean DBP } \\
\text { (mmHg) }\end{array}$ & $87.82+8.9$ & $88.08+10.1$ & 0.93 \\
\hline $\begin{array}{l}\text { 7th day mean pulse } \\
\text { (minute) }\end{array}$ & $88.92+8.6$ & $92.87+11.5$ & 0.21 \\
\hline Weight (kg) & $64.67+13.6$ & $67.01+14.5$ & 0.42 \\
\hline Surgical Complications & $7(12.2 \%)$ & $5(7.2 \%)$ & 0.47 \\
\hline Rejection & $3(5.2 \%)$ & $11(16 \%)$ & 0.86 \\
\hline Delayed Renal Function & $19(33.3 \%)$ & $12(17.3 \%)$ & 0.039 \\
\hline $\begin{array}{l}\text { 6th month GFR >60 } \\
\text { ml/min }\end{array}$ & $36(63.1 \%)$ & $38(55.1 \%)$ & 0.37 \\
\hline
\end{tabular}

LDD: Low Dose Dopamine, Hgb: Hemoglobin, Alb: Albumin, Cr: Creatinine, SBP: Systolic Blood Pressure, DBP: Diastolic Bloood Pressure, GFR: Glomerular Filtration Rate 
Table III. Factors affecting delayed graft function

\begin{tabular}{|l|l|l|l|}
\hline & \multicolumn{1}{|c|}{$\begin{array}{c}\text { Delayed Graft } \\
\text { Function (n=31) }\end{array}$} & $\begin{array}{c}\text { Non-Delayed } \\
\text { Graft Function } \\
(\mathbf{n}=95)\end{array}$ & $\begin{array}{c}\mathbf{p} \\
\text { value }\end{array}$ \\
\hline Receiving LDD & $19(61.2 \%)$ & $38(40 \%)$ & 0.06 \\
\hline $\begin{array}{l}\text { Living/deceased } \\
\text { transplantation }\end{array}$ & $15 / 16$ & $79 / 16$ & $<0.001$ \\
\hline Age (year) & $44.8+10.9$ & $37.01+11.6$ & $<0.001$ \\
\hline Sex (M/F) & $17 / 14$ & $47 / 48$ & 0.681 \\
\hline DM (n) & $3(33.3 \%)$ & $6(66.7)$ & 0.688 \\
\hline Donor HT (n) & $6(66.7 \%)$ & $3(33.3 \%)$ & $<0.001$ \\
\hline Donor age (year) & $48.6+15.7$ & $43.2+10.4$ & 0.06 \\
\hline Donor sex (M/F) & $10 / 10$ & $38 / 55$ & 0.466 \\
\hline $\begin{array}{l}\text { Renal replacement } \\
\text { treatment duration } \\
\text { (month) }\end{array}$ & $58.2+52.4$ & $34.7+45.3$ & 0.022 \\
\hline
\end{tabular}

LDD: Low Dose Dopamine, DM: Diabetes Mellitus, HT: Hypertension,

\section{DISCUSSION}

Postoperative LDD infusion therapy was frequently used in patients undergoing renal transplantation at the beginning of the last decade. The initial aim of this treatment was to increase renal blood flow by vasodilation and improve GFR. In this study, we found that LDD was associated with the presence of delayed graft function, overall graft function, mortality, and graft loss. Indeed, Doppler ultrasonography studies of renal vasculature showed administration of $2.5 \mathrm{mg} / \mathrm{kg} / \mathrm{min}$ of dopamine resulted in increased peak systolic velocity in the arcuate arterioles and reduced the resistive index $[10,11]$. Calculation of renal blood flow was useful for determining these effects of dopamine on the kidney. However, there have been no parameters to measure the effects of LDD in denervated tissue, such as transplanted kidneys. Thus far, few studies have investigated the effects of dopamine on the blood flow of transplanted kidneys. Dalton et al., evaluated renal blood flow in 20 transplant patients and found no significant differences between patients receiving 3 $\mu \mathrm{g} / \mathrm{kg} / \mathrm{min}$ LDD and the non-LDD group (importantly, renal blood flow calculation was based on para-aminohippuric acid clearance) [5]. In another study, Spicer et al., used Doppler ultrasound to evaluate renal blood flow in patients who received $2.5 \mu \mathrm{g} / \mathrm{kg} / \mathrm{min}$ LDD infusion; renal blood flow was found to be similar in patients with and without LDD treatment [6]. Thus far, no clinical studies have shown positive efficacy of LDD in improving renal function $[3,5,12-14]$. In the present study, in accordance with the findings of previous investigations, there was no significant difference in GFR at 6 months postoperatively (based on Cr values) between patients in the LDD and non-LDD groups in the kidney transplant population.

A significant clinical indicator of improvement in renal blood flow and $\mathrm{Cr}$ clearance of LDD is elevated urine output. One study showed that patients who received LDD for 4 days had higher urine output, compared to patients who did not receive LDD [14]. Flancbaum et al., also reported a significant increase in urine output in patients who received LDD, but found no difference in urinary sodium excretion between the two groups [15]. Hosseinzadeh et al., reported the time to initiate diuresis earlier in the LDD group in unrelated renal transplant patients [16]. In these studies, administration of LDD led to elevated urine output, but did not affect $\mathrm{Cr}$ clearance. In the present study, there were no significant differences between the LDD and non-LDD groups in urine output and Cr levels during the 7 -day postoperative period. In the total patient population, patients with lower $\mathrm{Cr}$ levels at 6 months postoperatively had higher urine output in the immediate postoperative period. This may be a result of good hydration in the postoperative period, rather than an effect of LDD.

Delayed graft function, whether transplantation is performed from a living or deceased donor, is an important condition that increases short and long-term morbidity and mortality as well as decreasing graft survival [17]. Risk factors for delayed graft function are deceased donor, donor characteristics (e.g., donor hypertension, elderly donor, marginal donor, and high donor $\mathrm{Cr}$ ), long cold ischemia time, and body mass index [18]. Delayed graft function constitutes acute kidney injury due to ischemia of the kidney, independent of the risk factor. LDD directly affects kidney hemodynamics [19]. LDD has been presumed to protect patients from ischemia by exploiting its vasodilating effects in the kidney. Therefore, LDD administration was expected to reduce the risk of delayed graft function development. However, in the present study, the rate of delayed graft function was greater in the LDD group than in the non-LDD group. However, patient age, number of patients with a deceased donor, the presence of hypertension in the donor, and the durations of renal replacement treatment were significantly different between the groups. Therefore, LDD may not be the direct cause of delayed graft function. The difference in rates of delayed graft function between the LDD and nonLDD groups can be explained by the higher rate of deceased donor transplantation in the LDD group. Further studies in larger cohorts are required to confirm this finding.

Another factor that affects graft survival in renal transplant patients is the frequency of acute rejection. Several studies have been conducted to investigate the association of peritransplant dopamine administration with rejection; notably, factors impairing renal blood flow (e.g., deceased donor transplantation and prolonged ischemia time) were associated with acute rejection. Grundmann et al, reported that the number of patients who developed rejection within 1 week was significantly higher in the LDD group, whereas the number of patients who experienced rejection within 3 weeks was similar between LDD and non-LDD groups [14]. In another study, the rejection rates at 28 days post-transplantation were similar between patients with and without LDD [3]. Dönmez et al., reported no difference in rejection attacks between patients with and without LDD [13]. In the present study, consistent with previously reported findings, the rejection rates were similar in the LDD and non-LDD groups.

The side effects of postoperative vasopressor use in patients include tachycardia, arrhythmia, increased cardiac backload, increased myocardial oxygen demand, intestinal ischemia, electrolyte disturbance, and vasoconstriction of the extremities 
[19]. With respect to the side effect profile of dopamine use, one study showed a greater incidence of tachycardia (pulse $>100$ ) in the group receiving LDD [14]; no significant differences in blood pressure or pulse values related to LDD use were observed in other studies $[5,6,16]$. In the present study, there were no significant differences in 7-day postoperative blood pressure and pulse follow-up between the LDD and non-LDD groups. Therefore, we concluded that early post-transplant vasopressor use did not cause any serious side effects in our study.

Although, the present study included a sufficient number of patients to demonstrate the positive or negative effects of LDD, it also had some limitations. The most important limitation was its retrospective design. In addition, because of the risk of infection, central venous catheters were not placed in all patients, and fluid balances were monitored by measurements of the amounts of fluid that each patient received and excreted. Some invasive or noninvasive tests (e.g., renal Doppler ultrasound, central venous catheterization, arterial pressure monitoring, urine $\mathrm{Na}$ excretion, and/or Cr clearance) are necessary to accurately determine the volume assessment and renal blood flow of kidney transplant recipients. However, it is more appropriate to evaluate the parameters used in daily practice, to ensure that the results reflect clinical practice. Additional limitations included lack of data regarding cold ischemia time and HLA mismatch number.

The abandonment of LDD in renal transplantation has been largely based on evidence from studies on its effect in acute kidney injury. In our study, we demonstrated that the routine administration of LDD did not provide any additional benefit with regard to increasing graft survival in kidney transplant recipients compared to those not receiving LDD. In our clinic, the use of LDD was discontinued in early 2013. Consistent with the findings of previous studies, our results confirmed that perioperative LDD infusion did not provide additional benefit in patients who underwent kidney transplantation. Nevertheless, dopamine remains a promising agent, because its administration in kidney donors has recently been reported to improve graft function [20]. Perhaps, based on the findings of future studies, giving dopamine infusion to the donor kidneys to improve graft function before transplant may become a routine procedure.

\section{Acknowledgments}

We would like to thank Nurse Fatma Basyigit Ucar for her great help in patient care and data collection.

\section{Compliance with Ethical Standards}

Ethical Approval: This study was approved by the Institutional Review Board of Marmara University, School of Medicine (approval number 09.2017.266). All patients provided written informed consent.

Financial Support: The authors have no relevant financial information to disclose.

Conflict of Interest: The authors have no potential conflicts to declare.
Author Contributions:. Literature search: NSD and AV, Study design: NSD and AV, Lesiglative applications: NSD, AV, CY and ST, Data collection: NSD, AV, HA, EA, CY, and ST. Supervision: NSD a AV and ST, Statistical advice: AV and HA, Statistical analysis: NSD, AV and HA, Data interpretation: NSD and AV, Drafting the article: NSD and AV. All authors approved the final version of the article.

\section{REFERENCES}

[1] Pollock DM, Arendshorst WJ. Tubuloglomerular feedback and blood flow autoregulation during DA1-induced renal vasodilation. Am J Physiol 1990;258(3 Pt 2):F627-35. doi: 10.1152/ajprenal.1990.258.3.F627

[2] Schenarts PJ, Sagraves SG, Bard MR, et al. Low-dose dopamine: a physiologically based review. Curr Surg 2006;63:219-25. doi: 10.1016/j.cursur.2005.08.008

[3] Ciapetti M, di Valvasone S, di Filippo A, Cecchi A, Bonizzoli M, Peris A. Low-dose dopamine in kidney transplantation. Transplant Proc 2009;41:4165-8. doi: 10.1016/j. transproceed.2009.08.058

[4] Hall J. Guyton and Hall Textbook of Medical Physiology. 13th Edition, Philadelphia: W B Saunders, 2015.

[5] Dalton RS, Webber JN, Cameron C, et al. Physiologic impact of low-dose dopamine on renal function in the early post renal transplant period. Transplantation 2005;79:1561-7. doi: 10.1097/01.tp.000.015.8431.81676.c4

[6] Spicer ST, Gruenewald S, O'Connell PJ, Chapman JR, Nankivell BJ. Low-dose dopamine after kidney transplantation: assessment by Doppler ultrasound. Clin Transplant 1999;13:479-83. doi: 10.1034/j.1399-0012.1999.130607.x

[7] Stevens PE, Levin A. Evaluation and management of chronic kidney disease: synopsis of the kidney disease: improving global outcomes 2012 clinical practice guideline. Ann Intern Med 2013;158:825-30. doi: 10.7326/0003-4819-158-11201306.040.00007

[8] Singh RP, Farney AC, Rogers J, et al. Kidney transplantation from donation after cardiac death donors: lack of impact of delayed graft function on post-transplant outcomes. Clin Transplant 2011;25:255-64. doi: 10.1111/j.13990012.2010.01241.x

[9] Johnston O, O'Kelly P, Spencer S, et al. Reduced graft function (with or without dialysis) vs immediate graft function-a comparison of long-term renal allograft survival. Nephrol Dial Transplant 2006;21:2270-4. doi: 10.1093/ndt/gfl103

[10] Schwartz LB, Gewertz BL. The renal response to low dose dopamine. J Surg Res. 1988;45:574-88. doi: 10.1016/00224804(88)90147-3

[11] Yura T, Yuasa S, Fukunaga M, Badr KF, Matsuo H. Role for Doppler ultrasound in the assessment of renal circulation: effects of dopamine and dobutamine on renal hemodynamics in humans. Nephron 1995;71:168-75. doi: 10.1159/000188707

[12] Carmellini M, Romagnoli J, Giulianotti PC, et al. Dopamine lowers the incidence of delayed graft function in transplanted 
kidney patients treated with cyclosporine A. Transplant Proc 1994;26:2626-9. doi: Accession Number:7940818

[13] Dönmez A, Karaaslan D, Sekerci S, Akpek E, Karakayali H, Arslan G. The effects of diltiazem and dopamine on early graft function in renal transplant recipients. Transplant Proc 1999;31:3305-6. doi: 10.1016/s0041-1345(99)00736-8

[14] Grundmann R, Kindler J, Meider G, Stöwe H, Sieberth HG, Pichlmaier H. Dopamine treatment of human cadaver kidney graft recipients: a prospectively randomized trial. Klin Wochenschr 1982;60:193-7. doi: 10.1007/bf01715586

[15] Flancbaum L, Dick M, Choban PS, Dasta JP. Effects of lowdose dopamine on urine output in oliguric, critically ill, renal transplant patients. Clin Transplant 1998;12:256-9.

[16] Hosseinzadeh H, Golzari SE, Abravesh M, et al. Effect of low dose dopamine on early graft function in living unrelated kidney donors. Urol J 2012;9:389-96.
[17] Humar A, Johnson EM, Payne WD, et al. Effect of initial slow graft function on renal allograft rejection and survival. Clin Transplant 1997;11:623-7.

[18] Irish WD, Ilsley JN, Schnitzler MA, Feng S, Brennan DC. A risk prediction model for delayed graft function in the current era of deceased donor renal transplantation. Am J Transplant 2010;10:2279-86. doi: 10.1111/j.1600-6143.2010.03179.x

[19] O'Hara JF, Jr. Low-dose "renal" dopamine. Anesthesiol Clin North Am 2000;18:835-51, ix. doi: 10.1016/s08898537(05)70197-8

[20] Schnuelle P, Schmitt WH, Weiss C, et al. Effects of dopamine donor pretreatment on graft survival after kidney transplantation: A randomized trial. Clin J Am Soc Nephrol 2017;12:493-501. doi: 10.2215/cjn.07600716 